Polymer Journal, Vol. 39, No. 6, pp. 622-631 (2007)

(C) 2007 The Society of Polymer Science, Japan

\title{
Electrospun Gelatin Fibers: Effect of Solvent System on Morphology and Fiber Diameters
}

\author{
Nuanchan ChOKTAweesap, ${ }^{1}$ Kunawan ARAyAnarakul,${ }^{1}$ Duangdao Aht-ong,,${ }^{1, \dagger}$ \\ Chidchanok MEECHAISUE, ${ }^{2}$ and Pitt SUPAPHOL ${ }^{3, \dagger}$
}

\author{
${ }^{1}$ Department of Materials Science, Faculty of Science, Chulalongkorn University, Bangkok 10330, Thailand \\ ${ }^{2}$ Department of Materials Technology, Faculty of Science, Ramkhamhaeng University, Bangkok 10240, Thailand \\ ${ }^{3}$ Technological Center for Electrospun Fibers and The Petroleum and Petrochemical College, \\ Chulalongkorn University, Bangkok 10330, Thailand
}

(Received December 12, 2006; Accepted March 22, 2007; Published April 27, 2007)

\begin{abstract}
Gelatin, a naturally-occurring biopolymer, was electrospun in the present contribution. Gelatin solutions were prepared in either single solvent system [i.e., glacial acetic acid (AA)] or mixed solvent systems [i.e., AA/ 2,2,2-trifluoroethanol (TFE), AA/dimethyl sulfoxide (DMSO), AA/ethylene glycol (EG), and AA/formamide (F)]. The electrospinning was carried out under a fixed electrostatic field strength of $7.5 \mathrm{kV} / 7.5 \mathrm{~cm}$ and the polarity of the emitting electrode was positive. The effects of these solvent systems on morphology and/or size of the electrospun materials were observed by scanning electron microscopy (SEM). Electrospinning of 15-29\% w/v gelatin solutions in AA produced beads, beaded fibers, and smooth fibers, depending on the concentration range. Only smooth fibers were observed at the concentration range of $21-29 \% \mathrm{w} / \mathrm{v}$, with their average diameter ranging between 214 and $839 \mathrm{~nm}$. The addition of TFE as a co-solvent or another modifying liquid of DMSO, EG, or F helped improve the electrospinnability of the resulting gelatin solution. Among the three modifying liquids, DMSO and EG contributed to the formation of smooth gelatin fibers with reduced diameters when compared with those obtained from the solution in pure AA.

[doi:10.1295/polymj.PJ2006190]

KEY WORDS Electrospinning / Nanofibers / Gelatin / Solvent /
\end{abstract}

Electrostatic spinning or electrospinning is a process by which ultrafine fibers with diameters in nanometer to sub-micrometer range can be fabricated. ${ }^{1}$ This process deals with the application of an intense electrostatic field to a polymer liquid (i.e., solution or melt) across a finite distance. ${ }^{2-4}$ When a high electrostatic field is applied, charges accumulate on the surface of a droplet of the polymer liquid at the tip of the nozzle. With increasing electrostatic field strength, the Coulombic repulsion forces destabilize the partially-hemispherical shape of the droplet into a conical shape when a critical electrostatic field strength is reached. Further increasing the electrostatic field strength causes a charged stream of the polymer liquid (i.e., the charged jet) to be ejected from the apex of the cone. The charged jet travels in a straight trajectory for a short distance before undergoing a bending instability, ${ }^{5,6}$ which is thought to be additional mechanism responsible for the further thinning of the jet during its flight to a grounded collector.

Due to the unique characteristics of electrospun fibers, e.g., high surface area to volume or mass ratio and high density of pores in sub-micrometer length scale of the obtained as-spun non-woven mat, these fibers are excellent candidates for various biomedical applications (e.g., tissue scaffolds, wound dressing pads, vascular grafts, and carriers for drug delivery). ${ }^{7-15}$ Several natural polymers, e.g., silk and collagen, were successfully fabricated into ultrafine fibers by electrospinning. ${ }^{16-19}$ Gelatin, a natural polymer derived from collagen, has also been fabricated into nanofibrous form by electrospinning. ${ }^{20-23}$ Gelatin solutions in 2,2,2-trifluoroethanol (TFE) with concentration ranging from 5 to $12.5 \% \mathrm{w} / \mathrm{v}$ were electrospun into ultrafine fibers with an average diameter ranging between 100 and $340 \mathrm{~nm}^{22}$ Moreover, gelatin solutions in $98 \%$ formic acid with concentration ranging from 7 to $12 \mathrm{wt} . \%$ were electrospun into ultrafine fibers with an average diameter ranging between 70 and $170 \mathrm{~nm} .^{23}$

In recent years, focuses have been paid on the effect of solvent system on morphology of the electrospun fibers. Lee et $a l .{ }^{24}$ found that electrospinnability of poly( $\varepsilon$-caprolactone) (PCL) solutions was enhanced with the addition of $N, N$-dimethylformamide (DMF) to methylene chloride (MC). On the other hand, when toluene was added to $\mathrm{MC}$, the electrospinnability of the resulting PCL solutions decreased. Lee et al. ${ }^{25}$ found that electrospun poly(vinyl chloride) (PVC) fibers from PVC solutions in tetrahydrofuran (THF) showed a broad distribution of diameters ranging from about $500 \mathrm{~nm}$ to $6 \mu \mathrm{m}$, while those from PVC solutions

†o whom correspondence should be addressed (E-mail: duangdao.a@chula.ac.th, E-mail: pitt.s@chula.ac.th). 
Electrospun Gelatin Fibers: Effect of Solvent System

Table I. Properties of solvents and liquids used in this work

\begin{tabular}{|c|c|c|c|c|c|c|c|}
\hline Solvent & Structure & $\begin{array}{l}\text { Density } \\
\left(\mathrm{g} \cdot \mathrm{cm}^{-3}\right)\end{array}$ & $\begin{array}{c}\text { Viscosity } \\
\text { (cP) }\end{array}$ & $\begin{array}{c}\text { Boiling } \\
\text { point } \\
\left({ }^{\circ} \mathrm{C}\right)\end{array}$ & $\begin{array}{l}\text { Dipole } \\
\text { moment } \\
\text { (D) }\end{array}$ & $\begin{array}{c}\text { Dielectric } \\
\text { constant }\end{array}$ & $\begin{array}{c}\text { Surface } \\
\text { tension } \\
\left(\mathrm{mN} \cdot \mathrm{m}^{-1}\right)\end{array}$ \\
\hline Acetic acid (GAA) & & 1.05 & 1.12 & 118 & 1.68 & 6.15 & 26.90 \\
\hline 2,2,2-Trifluoroethanol (TFE) & & 1.38 & 1.24 & 74 & 2.52 & 8.55 & - \\
\hline Dimethyl sulfoxide (DMSO) & & 1.10 & 2.00 & 189 & 3.90 & 46.70 & 43.00 \\
\hline Ethylene glycol (EG) & & 1.11 & 16.13 & 197 & 2.20 & 37.70 & 47.00 \\
\hline Formamide $(\mathrm{F})$ & $\mathrm{H}_{2} \mathrm{~N}^{-}$ & 1.13 & 3.30 & 211 & 3.37 & 111.00 & 59.10 \\
\hline
\end{tabular}

in DMF showed diameters of only about $200 \mathrm{~nm}$. Liu and $\mathrm{Hsieh}^{26}$ studied the effect of solvent system on the electrospinnability of cellulose acetate (CA) solutions and reported that while CA solutions in pure solvents of acetone, acetic acid, and $\mathrm{N}, \mathrm{N}$-dimethylacetamide (DMAc) did not provide the formation of continuous fibers, blending of DMAc with either acetone or acetic acid produced suitable electrospinnable systems.

Recently, Wannatong et al. ${ }^{27}$ investigated the effect of six solvents [i.e., acetic acid, acetonitrile, $m$-cresol, toluene, tetrahydrofuran (THF), and dimethylformamide (DMF)] on morphology and size of the electrospun polystyrene (PS) fibers. Fiber diameters decreased with increasing density and boiling point of the solvents. A large difference between the solubility parameters of PS and the solvent was responsible for the bead-on-string morphology observed. Productivity of the fibers increased with increasing dielectric constant and dipole moment of the solvents. In a subsequent work, Jarusuwannapoom et al. ${ }^{28}$ investigated the effects of eighteen solvents and their properties on electro-spinnability of PS solutions and appearance of the as-spun fibers. Among the eighteen solvents [i.e., benzene, $t$-butylacetate, carbontetrachloride, chlorobenzene, chloroform, cyclohexane, decahydronaphthalene (decalin), 1,2-dichloroethane (DCE), DMF, 1,4-dioxane, ethylacetate (EA), ethylbenzene, hexane, methylethylketone (MEK), nitrobenzene, THF, 1,2,3,4tetrahydronaphthalene (tetralin), and toluene], only the PS solutions in DCE, DMF, EA, MEK, and THF produced fibers with high enough productivity.

Instead of using $\mathrm{TFE}^{22}$ and formic acid $^{23}$ as the solvent for dissolving gelatin, glacial acetic acid (AA) was used as the solvent in the present work. Mixed solvents between AA and another solvent or liquid (i.e., TFE, dimethyl sulfoxide (DMSO), ethylene glycol (EG), and formamide (F)] were also used to pre- pare the gelatin solutions. The effects of either the single or the mixed solvent system on morphological appearance and/or size of the resulting electrospun gelatin fibers were investigated by scanning electron microscopy (SEM). The main objective of the present work was to seek for a wider selection of solvent systems that could be used to prepare electrospun gelatin fibers, as some applications, e.g., carriers for drug delivery, may call for a wide selection of solvent systems that can be used to prepare the electrospinnable spinning solutions of gelatin and the active ingredient(s) of choice.

\section{EXPERIMENTAL}

\section{Materials}

Porcine gelatin powder was purchased from Ajax (Australia). The solvents and the modifying liquids used in this work were glacial acetic acid [AA; Labscan (asia) (Thailand)], 2,2,2-trifluoroethanol [TFE; Labscan (asia) (Thailand)], dimethyl sulfoxide [DMSO; Sigma-Aldrich (Germany)], ethylene glycol [EG; Fluka (USA)], and formamide [F; Asia Pacific Specialty Chemicals (Germany)]. These chemicals were of analytical reagent grade and used as-received. The properties of these solvents and the modifying liquids are summarized in Table I. ${ }^{29}$

\section{Preparation and Characterization of Spinning Solu- tions}

Gelatin solutions were prepared in AA and some mixed solvent systems of AA and another solvent or liquid (i.e., TFE, DMSO, EG, and F) in various compositional ratios. Specifically, the compositional ratios of AA and TFE were 90:10, 80:20, 70:30, 60:40, 50:50, and 40:60 v/v, while the compositional ratios of AA and another liquid (i.e., DMSO, EG, and F) 
were 97:3, 95:5, 93:7, and 91:9 v/v, respectively. The solutions of gelatin in AA were prepared in various concentrations ranging from 15 to $29 \% \mathrm{w} / \mathrm{v}$, whereas those of gelatin in mixed solvent systems were fixed at the concentration of $19 \% \mathrm{w} / \mathrm{v}$. Prior to electrospinning, all of the as-prepared solutions were measured for their shear viscosity, surface tension, and conductivity by a Brookfield DV-III programmable rheometer, a Krüss DSA 10-Mk2 drop shape analyzer, and a Orion 160 conductivity meter, respectively.

\section{Electrospinning Process}

Electrospinning was carried out by first stocking each of the as-prepared gelatin solutions in a 3-mL glass syringe. A blunt-ended gauge-20 stainless steel hypodermic needle was used as the nozzle. A piece of aluminum ( $\mathrm{Al})$ sheet wrapped round a piece of thick poly(methyl methacrylate) sheet was used as the screen collector. The emitting electrode of positive polarity from a Gamma High-Voltage Research DES30PN/M692 DC power supply (Florida, USA) was attached to the needle and the grounding electrode to the collector. Unless noted otherwise, solutions were electrospun under a fixed electrostatic field strength (EFS) of $7.5 \mathrm{kV} / 7.5 \mathrm{~cm}$ over a fixed collection time of about $10 \mathrm{~min}$.

\section{Morphological Observation}

The morphological appearance of the as-spun products was observed by a JEOL JSM-6400 scanning electron microscope (SEM). The specimens for SEM observation were prepared by cutting an $\mathrm{Al}$ sheet covered with the as-spun products and the cut section was carefully affixed on a copper stub. Each specimen was gold-coated using a Balzers Union SCD 040 sputtering device prior to SEM observation. Diameters of the as-spun fibers were measured directly from various SEM images taken for each specimen, from which at least 100 measurements for each specimen were analyzed to obtain an average value as well as the standard deviation.

\section{RESULTS AND DISCUSSION}

\section{Single Solvent System}

Both glacial acetic acid (AA) and 2,2,2-trifluoroethanol (TFE) were able to dissolve gelatin powder into homogeneous solutions, while other liquids such as dimethyl sulfoxide (DMSO), ethylene glycol (EG), and formamide (F) were not. Since TFE has recently been studied as the solvent for electrospinning gelatin fibers, ${ }^{22} \mathrm{AA}$ was then used as the main solvent in this work.

Gelatin solutions in AA were prepared at various concentrations ranging from 15 to $29 \% \mathrm{w} / \mathrm{v}$ to inves-
Table II. Viscosity, surface tension, and conductivity of gelatin solutions in acetic acid and diameters of the resulting as-spun fibers as a function of the solution concentration

\begin{tabular}{ccccc}
\hline $\begin{array}{c}\text { Solution } \\
\text { concentration } \\
(\% \mathrm{w} / \mathrm{v})\end{array}$ & $\begin{array}{c}\text { Viscosity } \\
(\mathrm{cP})\end{array}$ & $\begin{array}{c}\text { Surface } \\
\text { tension } \\
\left(\mathrm{mN} \cdot \mathrm{m}^{-1}\right)\end{array}$ & $\begin{array}{c}\text { Conductivity } \\
\left(\mu \mathrm{S} \cdot \mathrm{cm}^{-1}\right)\end{array}$ & $\begin{array}{c}\text { Fiber } \\
\text { diameter } \\
(\mathrm{nm})\end{array}$ \\
\hline 15 & 114 & $26.70 \pm 0.04$ & 167 & $214 \pm 0.06$ \\
17 & 180 & $26.22 \pm 0.15$ & 205 & $220 \pm 0.06$ \\
19 & 250 & $26.75 \pm 0.72$ & 224 & $271 \pm 0.11$ \\
21 & 400 & $26.00 \pm 0.05$ & 254 & $337 \pm 0.09$ \\
23 & 594 & $25.92 \pm 0.06$ & 296 & $413 \pm 0.08$ \\
25 & 699 & $25.80 \pm 0.05$ & 304 & $502 \pm 0.06$ \\
27 & 1217 & $25.72 \pm 0.05$ & 317 & $616 \pm 0.05$ \\
29 & 1586 & $24.68 \pm 0.09$ & 342 & $839 \pm 0.09$ \\
\hline
\end{tabular}

tigate the effect of the solution concentration on morphology and size of the as-spun gelatin fibers. Prior to electrospinning, some of the solution properties, i.e., shear viscosity, surface tension, and conductivity, were measured (see Table II). Both the viscosity and the conductivity of the solutions were found to increase, while the surface tension was found to decrease, with increasing solution concentration. The monotonous increase in the solution viscosity with increasing solution concentration was obviously a result of the increased molecular entanglements, while the monotonous increase in the solution conductivity with increasing solution concentration could be a result of the increase in the number of charged species resulting from the dissolution of gelatin in the acidic condition of the solutions. On the other hand, the increase in the solution concentration could adversely affect the cohesiveness among the water molecules at the liquid/air interface, hence the observed slight reduction in the surface tension of the solutions.

The electrospinning of these solutions was carried out at a fixed applied electrostatic field strength (EFS) of $7.5 \mathrm{kV} / 7.5 \mathrm{~cm}$ (i.e., $1 \mathrm{kV} / \mathrm{cm}$ ) over a fixed collection time of about $10 \mathrm{~min}$. Figure 1 shows selected SEM images of the as-spun products from gelatin solutions of varying concentration (ranging between 15 and $29 \% \mathrm{w} / \mathrm{v}$ ). At low solution concentrations (i.e., between 15 and $19 \% \mathrm{w} / \mathrm{v}$ ), the presence of beads, either as discrete beads or beads on beaded fibers, was observed along with the presence of smooth fibers which were fused to one another at touching points. The beads disappeared altogether when the concentration of the solutions was between about 21 and 29\% w/v. Furthermore, the diameters of the as-spun gelatin fibers increased monotonically with increasing concentration of the solutions (see Table II), while the number of the as-spun fibers per unit area was found to decrease (results not shown). For beaded fibers, only the diameters of the fiber sections between beads were measured. Specifically, the 


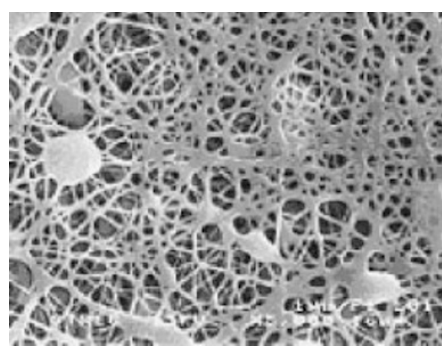

(a)

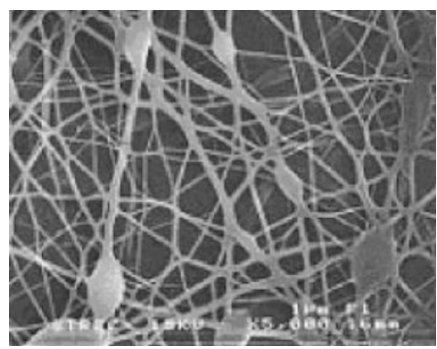

(c)

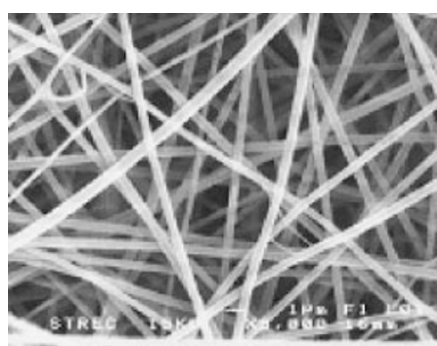

(e)

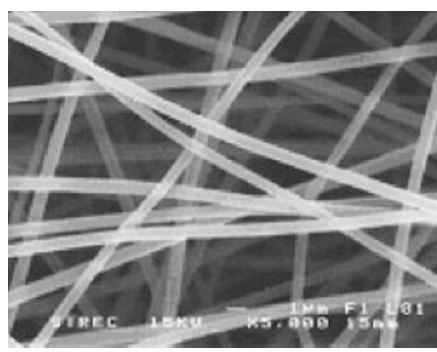

(g)

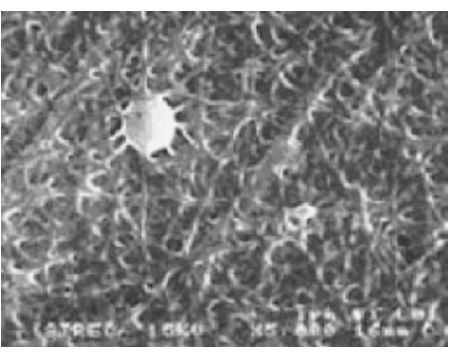

(b)

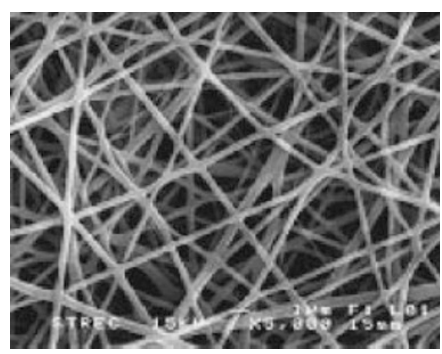

(d)

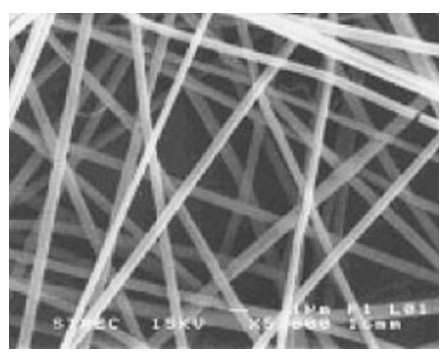

(f)

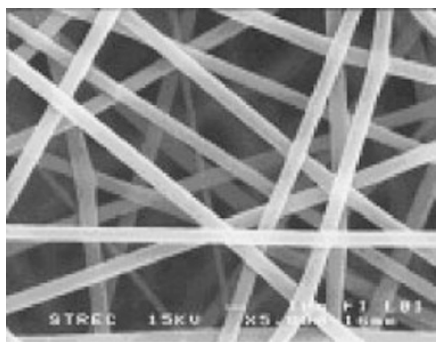

(h)

Figure 1. Selected SEM images (magnification $=5000 \mathrm{x}$; scale bar $=1 \mu \mathrm{m}$ ) of as-spun materials from gelatin solutions in glacial acetic acid of varying concentration: (a) 15, (b) 17, (c) 19, (d) 21, (e) 23, (f) 25, (g) 27, and (h) 29\% w/v, under a fixed electrostatic field strength of $7.5 \mathrm{kV} / 7.5 \mathrm{~cm}$.

average diameter of the as-spun gelatin fibers increased from about $214 \mathrm{~nm}$ at the solution concentration of $15 \% \mathrm{w} / \mathrm{v}$ to about $839 \mathrm{~nm}$ at the solution concentration of $29 \% \mathrm{w} / \mathrm{v}$. Comparatively, electrospinning of $5-12.5 \% \mathrm{w} / \mathrm{v}$ gelatin solutions in TFE produced fibers with an average diameter ranging between 100 and $340 \mathrm{~nm}^{22}$ and that of $7-12 \mathrm{wt} . \%$ gelatin solutions in $98 \%$ formic acid produced fibers with an average diameter ranging between 70 and $170 \mathrm{~nm}^{23}$

The formation of beaded and smooth fibers could be explained based on the interplay among the three major forces, that are Coulombic force, viscoelastic force, and surface tension. ${ }^{27}$ At low solution concentrations, the viscoelastic force, in comparison with both the electrostatic and the Coulombic stretching forces, was not enough to prevent either partial or total breakup of the charged jet and, as a result of the surface tension, either discrete beads or beaded fibers were formed. ${ }^{30,31}$ With increasing concentration of the solutions, the viscoelastic force was high enough to counter both the electrostatic and the Coulombic stretching forces, preventing both the partial and the total breakup of the charged jet. The monotonous increase in the viscoelastic force in comparison with both the electrostatic and the Coulombic stretching forces was also responsible for the monotonous increase in the fiber diameters with increasing solution concentration. 
Table III. Viscosity, surface tension, and conductivity of gelatin solutions (19\% w/v) in various mixed solvent systems and morphology and diameters of the resulting as-spun fibers as a function of the composition of the solvent mixture

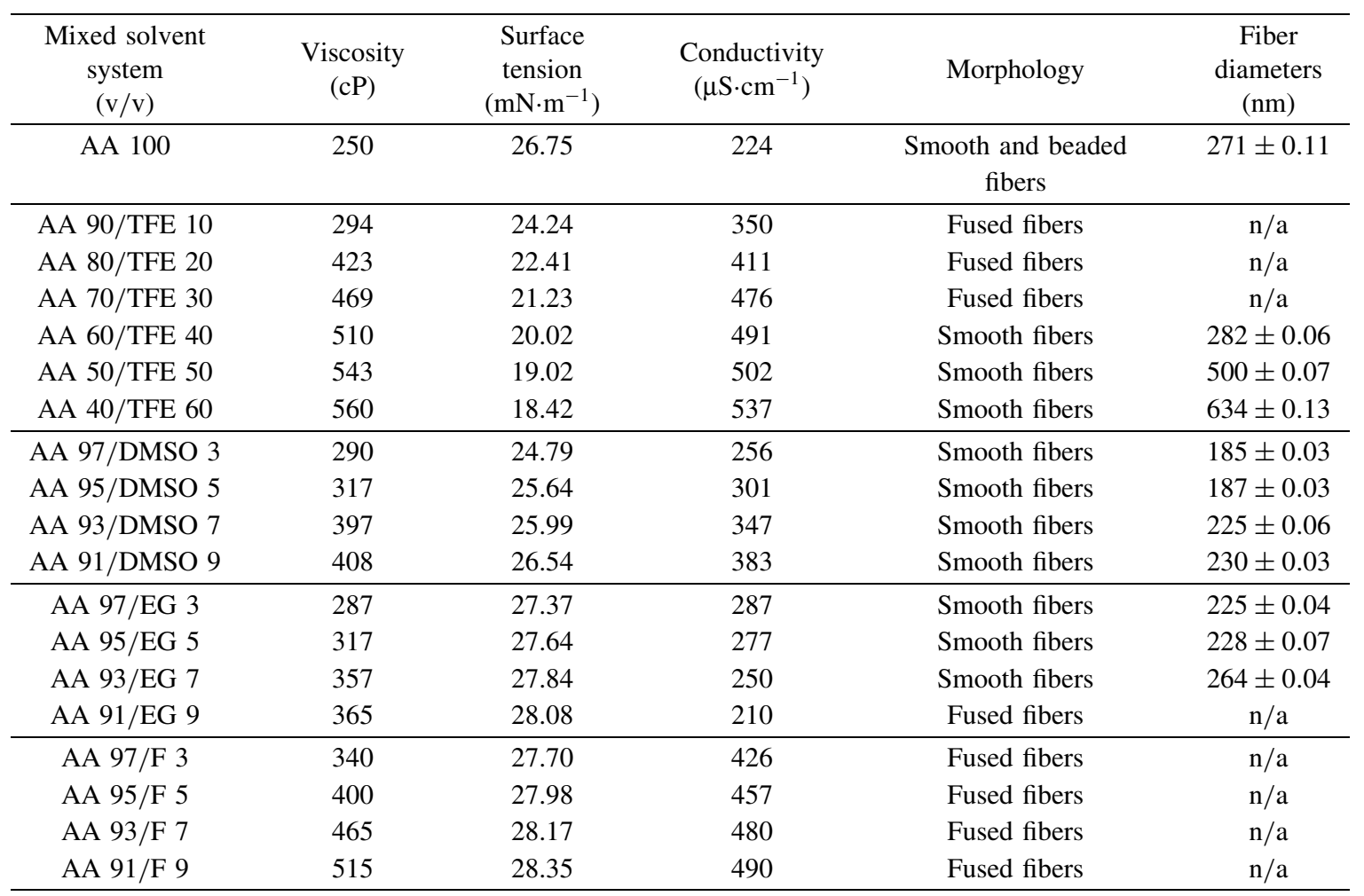

In order to observe the effect of EFS on morphology and size of the as-spun products, the EFS was varied (i.e., 7.5, 15.0, and $22.5 \mathrm{kV} / 7.5 \mathrm{~cm}$ ). Despite the variation in the applied electrical potential, the morphology of the as-spun products was similar to that shown in Figure 1. In addition, the diameters of the obtained as-spun gelatin fibers, at a given solution concentration, were also quite similar at all EFS values investigated (results not shown).

\section{Mixed-Solvent Systems}

The second solvent or liquid was mixed with AA to investigate the effect of its addition on some properties of the resulting gelatin solutions as well as the morphology and/or size of the as-spun gelatin fibers. Based on the results obtained on the single solvent system, $19 \% \mathrm{w} / \mathrm{v}$ of the gelatin solution was chosen to further investigate the effect of these mixed-solvent systems because the viscosity of the solution at the particular concentration in AA was high enough to allow the formation of beaded fibers with less beads when the solution was electrospun. Another important reason for choosing this particular concentration was to observe whether the addition of the second solvent or liquid was able to totally suppress the formation of beads (on the beaded fibers). Table III summarizes some of the solution properties, i.e., shear viscosity, surface tension, and conductivity, of the gelatin solu- tions in various mixed solvent systems. The property values of the gelatin solution in AA were also listed for comparison.

Glacial Acetic Acid and 2,2,2-Trifluoroethanol. AA and TFE are both good solvents for gelatin. Being chosen based on the fact that fluorinated alcohols, such as TFE and hexafluoroisopropanol (HFIP), though very expensive, are known good solvents for polypeptides, such as collagen, ${ }^{19}$ TFE was used as the solvent for successful electrospinning of gelatin (porcine skin; type A). ${ }^{22}$ Here, AA and TFE were mixed at the compositional ratios of 90:10, 80:20, 70:30, 60:40, 50:50, and 40:60 v/v, respectively. These mixtures were able to dissolve gelatin powder into clear solutions. Some of the solution properties, i.e., shear viscosity, surface tension, and conductivity, of the as-prepared gelatin solutions are summarized in Table III. Evidently, both the shear viscosity and the conductivity of the gelatin solutions in the mixed solvents increased with increasing TFE content, a direct result of the greater viscosity and dielectric constant values of TFE in comparison with those of AA (see Table I) that were responsible for the observed increase in both the property values of the gelatin solutions with increasing TFE content. On the contrary, the surface tension decreased with increasing TFE content.

Figure 2 shows selected SEM images of the as-spun 


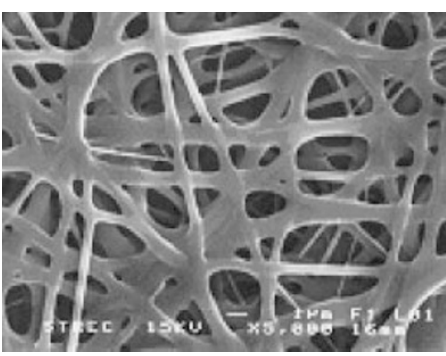

(a)

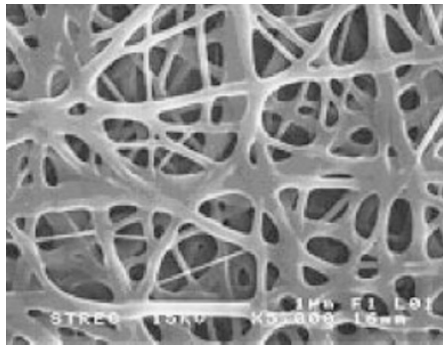

(c)

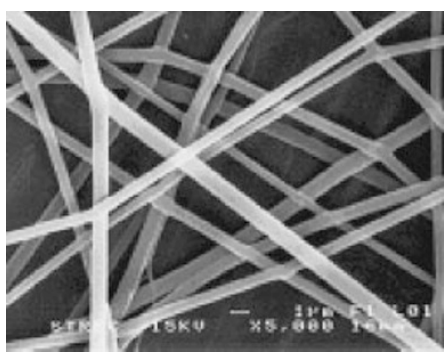

(e)

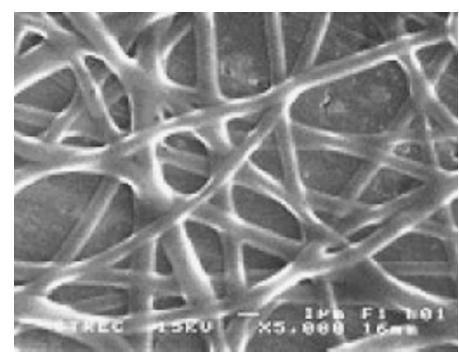

(b)

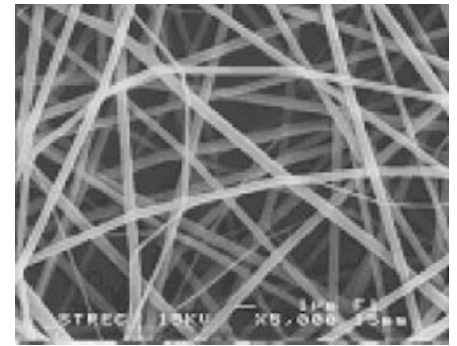

(d)

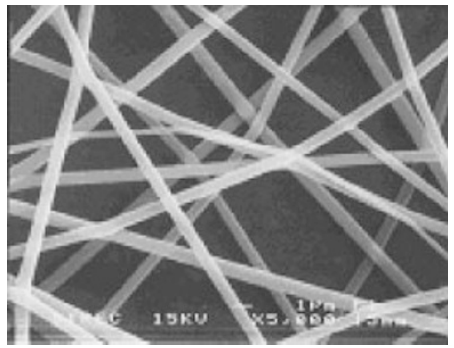

(f)

Figure 2. Selected SEM images (magnification $=5000 \mathrm{x}$; scale bar $=1 \mu \mathrm{m}$ ) of as-spun materials from $19 \% \mathrm{w} / \mathrm{v}$ gelatin solutions in a mixture between glacial acetic acid (AA) and 2,2,2-trifluoroethanol (TFE) under a fixed electrostatic field strength of $7.5 \mathrm{kV} / 7.5 \mathrm{~cm}$. The volumetric ratio between AA and TFE was varied: (a) 90:10, (b) 80:20, (c) 70:30, (d) 60:40, (e) 50:50, and (f) 40:60.

fibers from the gelatin solutions in mixed solvents of AA and TFE. While electrospinning of the $19 \% \mathrm{w} / \mathrm{v}$ gelatin solution in pure AA produced a combination of smooth and beaded fibers which fused to one another at touching points (see Figure 1b), electrospinning of the gelatin solutions in AA/TFE at the same concentration only resulted in the formation of smooth fibers. Interestingly, when the TFE content was lower than or equal to $30 \mathrm{vol} \%$, the obtained fibers appeared to fuse to one another at touching points as well. The fusing of the fibers at touching points was due to the incomplete evaporation of AA before the charged jet deposited on the Al screen. The tendency for complete evaporation of the solvent increased with the addition of TFE, due primarily to the much lower boiling of this solvent in comparison with AA (i.e., $74^{\circ} \mathrm{C}$ for TFE versus $118^{\circ} \mathrm{C}$ for AA; see Table I). The average diameter of the fibers that were spun from gelatin solutions in 60:40, 50:50, and 40:60 v/v $\mathrm{AA} / \mathrm{TFE}$ was about 280,500 , and $630 \mathrm{~nm}$, respectively. Obviously, in the presence of TFE, the as-spun fibers appeared to be larger, a direct result of the ob- served increase in the viscosity and the conductivity of the resulting solutions (see Table III).

Though not shown, electrospinning of the gelatin solutions in AA/TFE when the TFE content was lower than or equal to $30 \mathrm{vol} . \%$ at a different EFS of $15 \mathrm{kV} / 15 \mathrm{~cm}$ (still the same ratio between the applied electrical potential and the collection distance to that of $7.5 \mathrm{kV} / 7.5 \mathrm{~cm}$ ) resulted in the formation of smooth fibers with average diameter in the range of 250 to $270 \mathrm{~nm}$, while electrospinning of the solutions AA/TFE when the TFE content was greater than $30 \mathrm{vol} . \%$ (but not more than $60 \mathrm{vol} . \%$ ) produced the as-spun products similar to those shown in Figure 2. When the TFE content was lower than or equal to $30 \mathrm{vol} . \%$, the ejected jet could not dry during its flight from the nozzle to the collector at the collection distance of $7.5 \mathrm{~cm}$; therefore, with an increase in the collection distance to $15 \mathrm{~cm}$, the ejected jet had more time to 'dry' prior to deposition on the collector. On the contrary, when the TFE content was greater than $30 \mathrm{vol} . \%$, the increase in the collection distance to $15 \mathrm{~cm}$ had no obvious effect as the jet was able to 


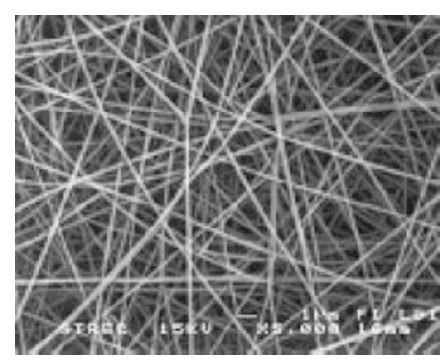

(a)

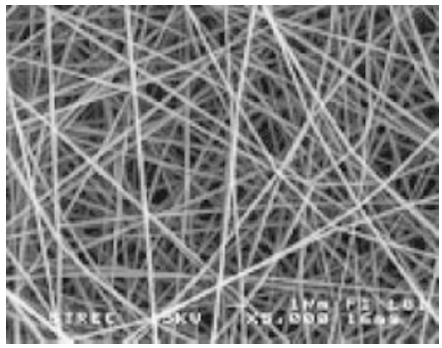

(c)

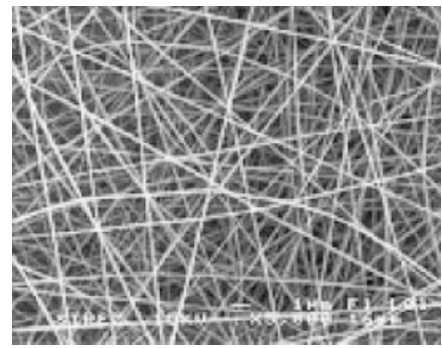

(b)

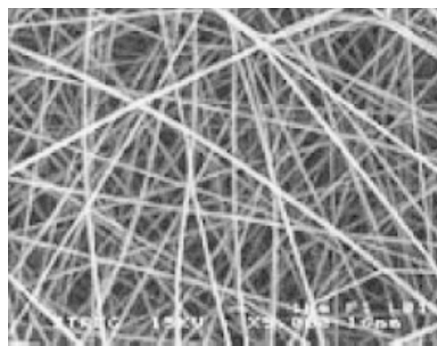

(d)

Figure 3. Selected SEM images (magnification $=5000 \mathrm{x}$; scale bar $=1 \mu \mathrm{m}$ ) of as-spun materials from $19 \% \mathrm{w} / \mathrm{v}$ gelatin solutions in a mixture between glacial acetic acid (AA) and dimethyl sulfoxide (DMSO) under a fixed electrostatic field strength of $7.5 \mathrm{kV} / 7.5 \mathrm{~cm}$. The volumetric ratio between AA and DMSO was varied: (a) 97:3, (b) 95:5, (c) 93:7, and (d) 91:9.

'dry' completely even at the shorter collection distance of $7.5 \mathrm{~cm}$.

Glacial Acetic Acid and Dimethyl Sulfoxide. DMSO is not a solvent for gelatin, but the reason for it being chosen as a modifying liquid was due to its moderately high dielectric constant, in comparison with that of AA (see Table I). Due to it being a non-solvent for gelatin, as much as 9 vol. \% of DMSO was mixed with AA to produce the mixed solvents at the compositional ratios of 97:3, 95:5, 93:7, and 91:9 v/v (AA/DMSO), respectively. These mixtures were still able to dissolve gelatin powder into clear solutions. Some of the solution properties, i.e., shear viscosity, surface tension, and conductivity, of the as-prepared gelatin solutions are summarized in Table III. Evidently, all of the property values of the gelatin solutions in the mixed solvents were greater than those of the gelatin solution in pure AA and were found to increase with increasing DMSO content, a direct result of the greater viscosity, surface tension, and viscosity values of DMSO in comparison with those of AA (see Table I).

Figure 3 shows selected SEM images of the as-spun fibers from the gelatin solutions in mixed solvents of AA and DMSO. While electrospinning of the 19\% $\mathrm{w} / \mathrm{v}$ gelatin solution in pure AA produced a combination of smooth and beaded fibers which fused to one another at touching points (see Figure 1b), electrospinning of the gelatin solutions in AA/DMSO at the same concentration produced only smooth fibers. Despite the obviously high boiling point of DMSO $\left(189^{\circ} \mathrm{C}\right.$; see Table I), the as-spun fibers did not fuse to one another at touching points. Interestingly, the as-spun fibers from the gelatin solutions in the mixed solvents appeared to be smaller than those from the solution in pure AA. However, with increasing DMSO content, the average diameter of the obtained fibers was found to increase, most likely a direct result of the observed increase in both the viscosity and the conductivity of the resulting solutions (see Table III).

Glacial Acetic Acid and Ethylene Glycol. Like DMSO, EG is not a solvent for gelatin, but it was chosen as a modifying liquid because its dielectric constant is marginally greater than that of AA (see Table I). Since it is not a solvent for gelatin, as much as 9 vol. \% of EG was mixed with AA to produce the mixed solvents [i.e., 97:3, 95:5, 93:7, and 91:9 v/v (GAA/EG)] that were still able to dissolve gelatin powder into clear solutions. Some of the solution properties, i.e., shear viscosity, surface tension, and conductivity, of the as-prepared gelatin solutions are summarized in Table III. Evidently, both the shear viscosity and the surface tension of the gelatin solutions in the mixed solvents were greater than those of the gelatin solution in pure AA and were found to increase with increasing EG content, a direct result of the greater viscosity and surface tension values of EG in comparison with those of AA (see Table I). On the other hand, the small amount of EG (i.e., 3 vol. \%) increased the conductivity of the solution markedly, but, with further increase in the EG content, the conductivity was found to decrease, with the property value of the solution containing 9vol. \% EG being lower than that of the solution in pure AA. 


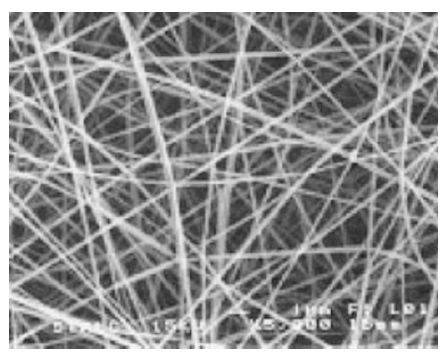

(a)

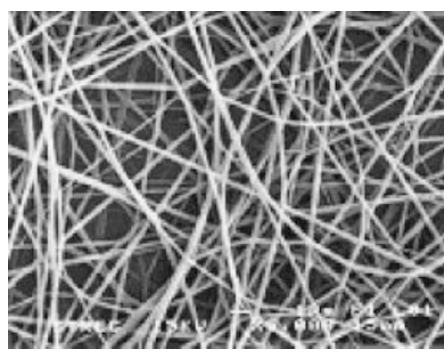

(c)

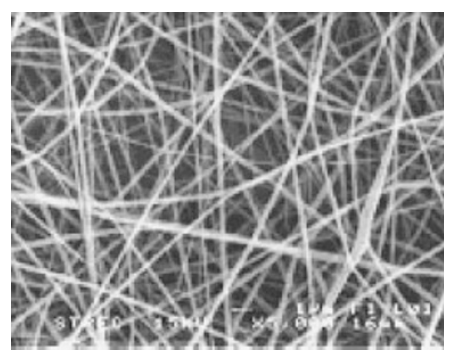

(b)

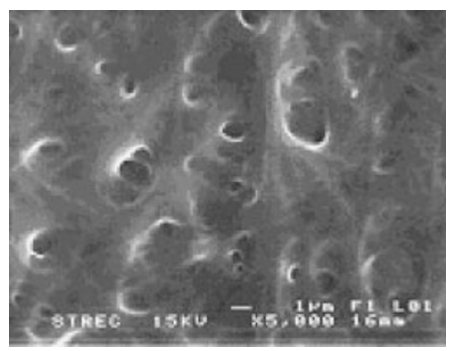

(d)

Figure 4. Selected SEM images (magnification $=5000 \mathrm{x}$; scale bar $=1 \mu \mathrm{m}$ ) of as-spun materials from $19 \% \mathrm{w} / \mathrm{v}$ gelatin solutions in a mixture between glacial acetic acid (AA) and ethylene glycol (EG) under a fixed electrostatic field strength of $7.5 \mathrm{kV} / 7.5 \mathrm{~cm}$. The volumetric ratio between AA and EG was varied: (a) 97:3, (b) 95:5, (c) 93:7, and (d) 91:9.

Figure 4 shows selected SEM images of the as-spun fibers from the gelatin solutions in mixed solvents of AA and EG. While electrospinning of the $19 \% \mathrm{w} / \mathrm{v}$ gelatin solution in pure AA produced a combination of smooth and beaded fibers which fused to one another at touching points (see Figure 1b), electrospinning of the gelatin solutions in AA/EG when EG content was lower than or equal to about $7 \mathrm{vol} \%$ at the same concentration produced only smooth fibers. Despite the considerably high boiling point of EG $\left(197^{\circ} \mathrm{C}\right.$; see Table I), the as-spun fibers did not fuse to one another at touching points. However, when the EG content was 9 vol. \%, the as-spun fibers fused completely to form a thin film on the $\mathrm{Al}$ screen. A likely explanation for this could be based on the competitive evaporation of the two solvents. Since the boiling point of $\mathrm{AA}$ is much lower than that of $\mathrm{EG}$ (i.e., $118^{\circ} \mathrm{C}$ for GAA versus $197^{\circ} \mathrm{C}$ for EG; see Table I), the evaporation of AA from the charged jet could occur in a much faster rate, causing the volumetric ratio between EG and AA to increase over time. At 91:9 of the mixed solvent, the ratio between the two components might be just right such that the amount of EG was just enough to keep the fibers in their wet state, causing them to fuse completely to one another.

Similar to the case of the mixed solvents between AA and DMSO, the as-spun fibers from the gelatin solutions in the mixed solvents of AA and EG appeared to be smaller than those from the solution in pure AA. However, with increasing EG content, the average diameter of the obtained fibers was found to increase, likely a direct result of the observed increase in the viscosity of the resulting solutions (see Table III).

Glacial Acetic Acid and Formamide. Similarly to the cases of DMSO and EG, F is not a solvent for gelatin, but it was chosen as a modifying liquid because of its extremely high boiling point, dielectric constant, and surface tension values (see Table I). Since it is not a solvent for gelatin, as much as $9 \mathrm{vol} . \%$ of $\mathrm{F}$ was mixed with AA to produce the mixed solvents [i.e., 97:3, 95:5, 93:7, and 91:9 v/v $(\mathrm{GAA} / \mathrm{F})]$ that were still able to dissolve gelatin powder into clear solutions. Some of the solution properties, i.e., shear viscosity, surface tension, and conductivity, of the as-prepared gelatin solutions are summarized in Table III. Like DMSO, all of the property values of the gelatin solutions in the mixed solvents were greater than those of the gelatin solution in pure AA and were found to increase with increasing $\mathrm{F}$ content, a direct result of the greater viscosity, surface tension, and viscosity values of $F$ in comparison with those of AA (see Table I).

Figure 5 shows selected SEM images of the as-spun fibers from the gelatin solutions in mixed solvents of AA and F. While electrospinning of the $19 \% \mathrm{w} / \mathrm{v}$ gelatin solution in pure AA produced a combination of smooth and beaded fibers which fused to one another at touching points (see Figure 1b), electrospinning of the gelatin solutions in $\mathrm{AA} / \mathrm{F}$ at the same concentration resulted only in the formation of fused fibers, most likely a result of the extremely high boiling point of $\mathrm{F}$ in comparison with that of AA (i.e., $118^{\circ} \mathrm{C}$ for AA versus $211^{\circ} \mathrm{C}$ for $\mathrm{F}$; see Table I). As previously noted, during the transport of the charged jet to the 


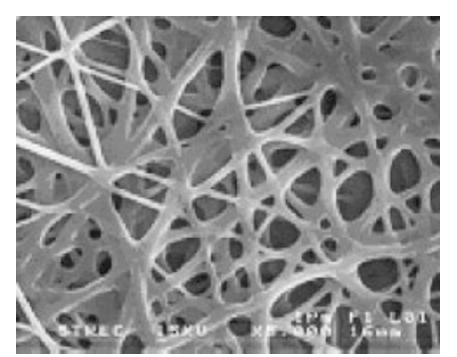

(a)

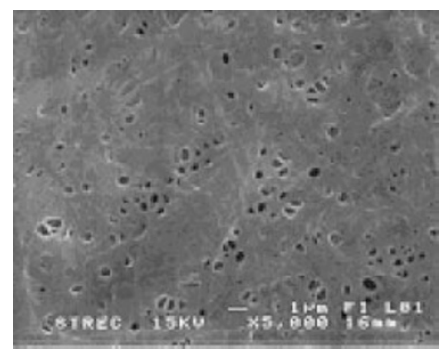

(c)

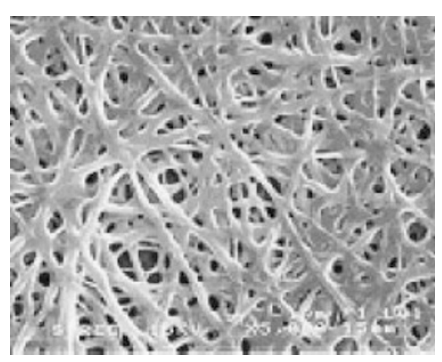

(b)

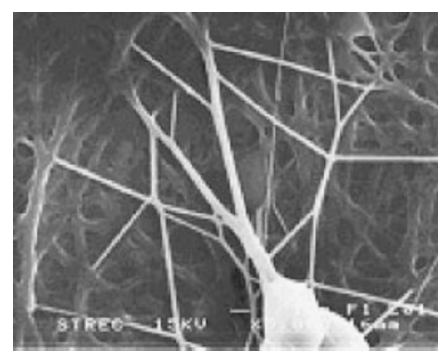

(d)

Figure 5. Selected SEM images (magnification $=5000 \mathrm{x}$; scale bar $=1 \mu \mathrm{m}$ ) of as-spun materials from $19 \% \mathrm{w} / \mathrm{v}$ gelatin solutions in a mixture between glacial acetic acid (AA) and formamide $(\mathrm{F})$ under a fixed electrostatic field strength of $7.5 \mathrm{kV} / 7.5 \mathrm{~cm}$. The volumetric ratio between AA and F was varied: (a) 97:3, (b) 95:5, (c) 93:7, and (d) 91:9.

Al screen collector, competitive evaporation of the solvents resulted in an increase in the actual content of $\mathrm{F}$, due to the much faster evaporation of AA in comparison with F. Clearly, the fusing of the as-spun gelatin products was more pronounced, when the content of $\mathrm{F}$ in the mixed solvents increased. Similar to the case of electrospinning of the gelatin solutions in AA/TFE, electrospinning of the gelatin solutions in $\mathrm{AA} / \mathrm{F}$ at the EFS of $15 \mathrm{kV} / 15 \mathrm{~cm}$ produced smooth fibers with relatively thinner fibers. These fibers were not fused as the solvents appeared to 'dry' more readily at increased collection distance, except for the fibers that obtained from the solution with the highest content of $\mathrm{F}$ that still fused to one another.

\section{CONCLUSION}

The present contribution reported the effect of either single or mixed solvent system on the electrospinning of gelatin fibers. The single solvent system was based on glacial acetic acid (AA), while the mixed solvent systems were based on mixtures between AA and another solvent or modifying liquid, i.e., 2,2,2-trifluoroethanol (TFE), dimethyl sulfoxide (DMSO), ethylene glycol (EG), and formamide (F). Among these, only AA and TFE were good solvents for gelatin. The effects of these solvent systems on morphology and/or size of the electrospun materials were observed by scanning electron microscopy (SEM). The electrospinning was carried out under a fixed electrostatic field strength of $7.5 \mathrm{kV} / 7.5 \mathrm{~cm}$ and the polarity of the emitting electrode was positive.
Electrospinning of $15-29 \% \mathrm{w} / \mathrm{v}$ gelatin solutions in AA produced beads, beaded fibers, and smooth fibers, depending on the concentration range. Only smooth fibers were observed at the concentration range of $21-29 \% \mathrm{w} / \mathrm{v}$. The obtained fibers exhibited the average diameter in the range of $214-839 \mathrm{~nm}$, with the value being found to increase with increasing solution concentration. The addition of TFE as a co-solvent or another modifying liquid of DMSO, EG, or F helped suppress the bead formation, likely a result of the observed increase in the viscosity and/or the conductivity of the resulting gelatin solutions. Due to their being non-solvents for gelatin, only as much as 9 vol. \% of DMSO, EG, and F could be mixed with AA to result in a mixture that was still able to dissolve gelatin into a clear solution. Among the three modifying liquids, DMSO and EG helped improve the electrospinnability of the gelatin solution and the obtained fibers were smaller in their diameters in comparison with those obtained from the gelatin solution in pure AA.

Acknowledgment. The authors acknowledged partial support received from a) the National Research Council of Thailand (NRCT), b) Chulalongkorn University (through invention and research grants from the Ratchadapesek Somphot Endowment Fund), c) the Petroleum and Petrochemical Technology Consortium [through a Thai governmental loan from Asian Development Bank (ADB)], and d) the Petroleum and Petrochemical College (PPC), Chulalongkorn University. 


\section{REFERENCES}

1. Z. M. Huang, Y. Z. Zhang, M. Kotaki, and S. Ramakrishna, Compos. Sci. Technol., 63, 2223 (2003).

2. J. Doshi and D. H. Reneker, J. Electrostatics, 35, 151 (1995).

3. D. H. Reneker and I. Chun, Nanotechnology, 7, 216 (1996).

4. A. Frenot and I. S. Chronakis, Curr. Opin. Colloid Interface Sci., 8, 64 (2003).

5. D. H. Reneker, A. L. Yarin, H. Fong, and S. Koombhongse, J. Appl. Phys., 87, 4531 (2000).

6. A. L. Yarin, S. Koombhongse, and D. H. Reneker, J. Appl. Phys., 89, 3018 (2001).

7. H. Yoshimoto, Y. M. Shin, H. Terai, and J. P. Vacanti, Biomaterials, 24, 2077 (2003).

8. I. K. Kwon, S. Kidoaki, and T. Matsuda, Biomaterials, 26, 3929 (2005).

9. W. J. Li, R. Tuli, X. Huang, P. Laquerriere, and R. S. Tuan, Biomaterials, 26, 5158 (2005).

10. K. Fujihara, M. Kotaki, and S. Ramakrishna, Biomaterials, 26, 4139 (2005).

11. S. A. Riboldi, M. Sampaolesi, P. Neuenschwander, G. Cossu, and S. Mantero, Biomaterials, 26, 4606 (2005).

12. Y. H. Lee, J. H. Lee, I. G. An, C. Kim, D. S. Lee, Y. K. Lee, and J. D. Nam, Biomaterials, 26, 3165 (2005).

13. X. Zong, H. Bien, C. Y. Chung, L. Yin, D. Fang, B. S. Hsiao, B. Chu, and E. Entcheva, Biomaterials, 26, 5330 (2005).

14. Z. Ma, M. Kotaki, T. Yong, W. He, and S. Ramakrishna, Biomaterials, 26, 2527 (2005).

15. E. R. Kenawy, G. L. Bowlin, K. Mansfield, J. Layman, D. G. Simpson, E. H. Sanders, and G. E. Wnek, J. Controlled Release, 81, 57 (2002).

16. H. J. Jin, S. V. Fridrikh, G. C. Rutledge, and D. L. Kaplan,
Biomacromolecules, 3, 1233 (2002).

17. G. H. Altman, F. Diaz, C. Jakuba, T. Calabro, R. L. Horan, J. Chen, H. Lu, J. Richmond, and D. L. Kaplan, Biomaterials, 24, 401 (2003).

18. S. H. Kim, Y. S. Nam, T. S. Lee, and W. H. Park, Polym. J., 35, 185 (2003).

19. J. A. Matthews, G. E. Wnek, D. G. Simpson, and G. L. Bowlin, Biomacromolecules, 3, 232 (2002).

20. M. Li, M. J. Mondrinos, M. R. Gandhi, F. K. Ko, A. S. Weiss, and P. I. Lelkes, Biomaterials, 26, 5999 (2005).

21. M. Li, Y. Guo, Y. Wei, A. G. MacDiarmid, and P. I. Lelkes, Biomaterials, 27, 2705 (2006).

22. Z. Huang, Y. Z. Zhang, S. Ramakrishna, and C. T. Lim, Polymer, 45, 5361 (2004).

23. C. S. Ki, D. H. Baek, K. D. Gang, K. H. Lee, I. C. Um, and Y. H. Park, Polymer, 46, 5094 (2005).

24. K. H. Lee, H. Y. Kim, M. S. Khil, Y. M. La, and D. R. Lee, Polymer, 44, 1287 (2003).

25. K. H. Lee, H. Y. Kim, Y. M. La, D. R. Lee, and N. H. Sung, J. Polym. Sci., Part B: Polym. Phys., 40, 2259 (2002).

26. H. Liu and Y. L. Hsieh, J. Polym. Sci., Part B: Polym. Phys., 40, 2119 (2002).

27. L. Wannatong, A. Sirivat, and P. Supaphol, Polym. Int., 53, 1851 (2004).

28. T. Jarusuwannapoom, W. Hongrojjanawiwat, S. Jitjaicham, L. Wannatong, M. Nithitanakul, C. Pattamaprom, P. Koombhongse, R. Rangkupan, and P. Supaphol, Eur. Polym. J., 41, 409 (2005).

29. Compiled from http://trimen.pl/witek/ciecze/old_liquids. html.

30. C. Mit-uppatham, M. Nithitanakul, and P. Supaphol, Macromol. Chem. Phys., 205, 2327 (2004).

31. P. Supaphol, C. Mit-uppatham, and M. Nithitanakul, J. Polym. Sci., Part B: Polym. Phys., 43, 3699 (2005). 